\title{
Iranian Population Policy and Aging: New Health Concerns
}

\author{
Shahram Manoochehry ${ }^{1}$, Hamid Reza Rasouli ${ }^{*}$ \\ ${ }^{1}$ Trauma Research Center, Baqiyatallah University of Medical Sciences, Tehran, Iran \\ Corresponding Author: Hamid Reza Rasouli, M.Sc., Trauma Research Center, Baqiyatallah University of Medical Sciences, \\ Tehran, Iran. Tel/Fax: +98-21-88053766, Email: hr.rasouli64@gmail.com
}

Received April 15, 2017; Accepted May 31, 2017, Online Published June 15, 2017

Citation: Manoochehry S, Rasouli HR. Iranian population policy and aging: new health concerns. Int J Travel Med Glob Health. 2017;5(2):70-71. doi:10.15171/ijtmgh.2017.14.

\section{Dear Editor}

Iran's population policy underwent a bizarre fluctuation in recent decades. During the Iran-Iraq war (1979-1987), the total fertility rate was about $6.53 \%$. Following this period and owing to economic problems, the government reversed the population policy in 1988. A new population plan was officially proposed to reduce the rate of population growth. ${ }^{1}$ In the 2011 census, the birth rate was reported to have declined to $1.29 \% .^{2}$ Moreover, according to data from the World Health Organization (WHO), the life expectancy in Iran increased dramatically from 54.67 years in 1980 to 75.5 years in 2015 . Both these factors increased the rate of population aging (or the double-aging process). The migration of young adults to other countries has also accelerated this phenomenon.

The 2011 census observed a significant demographic change in the elderly population of Iran (the percentage of the elderly population increased from $7.27 \%$ to $8.20 \%$ from 2006 to 2011 , and to $8.65 \%$ in 2016). The aging population is predicted to rise to $10.5 \%$ in 2025 and to $21.7 \%$ in 2050 . Recently, considering the predictions relating to population aging, the government policy has changed. It is now pushing for an increase in the rate of population growth. ${ }^{2}$

As a result of population aging, the fluctuating population policy in Iran, and the lack of an evidence-based approach in making population policy decisions, the country may encounter a lack of capable human resources keeping in mind the increased old age dependency ratio (a greater elderly population with much fewer young people to support them). ${ }^{3}$

Ezeh et al show that a country with a low or negative growth faces rapid population aging, unsustainable loads on public pensions and healthcare systems, and slow economic growth. ${ }^{4}$ Aging will have a negative influence on Iran's economy, health, and social welfare. There will also be an increasing need for hospital beds, sanatoriums, healthcare workers, and specialists in geriatric medicine (which is lacking in the current health system). ${ }^{5}$

It is clear that serious action should be taken keeping in mind this dilemma. Improving the health and population policy by following a reasonable, evidence-based scientific approach-such as extending hospital beds, establishing geriatric medicine departments and more sanatoriums, and educating more healthcare workers-can be a solution to counter population aging. In this regard, the experience of western countries after the industrial revolution could be an excellent model for Iranian policy-makers.

\section{Authors' Contributions}

SM and HRR contributed equally to this study.

\section{Conflict of Interest Disclosures}

We declare that there is no conflict of interest.

Ethical Approval

Not applicable.

Funding/Support

This study did not have any grants.

\section{Acknowledgements}

We would like to thank Dr. Mohammad Hosein Kalantar Motamedi for his helpful advice in the preparation of this letter.

\section{References}

1. Haub C, Kent MM. World Population Data Sheet. Washington DC: Population Reference Bureau; 2007.

2. Statistical Center of Iran, The President's Office Deputy of Strategic Planning and Control. National population and housing Census 2011 (1390): Selected Findings. Tehran: Statistical Center of Iran; 2011. [Persian]. 
3. Noroozian M. The elderly population in iran: an ever growing concern in the health system. Iran J Psychiatry Behav Sci. $2012 ; 6(2): 1-6$.

4. Ezeh AC, Bongaarts J, Mberu B. Global population trends and policy options. Lancet 2012;380(9837):142-148. doi:10.1016/
S0140-6736(12)60696-5.

5. Moeeni M, Pourreza A, Torabi F, Heydari H, Mahmoudi M. Analysis of economic determinants of fertility in Iran: a multilevel approach. Int J Health Policy Manag. 2014;3(3):135-44. doi:10.15171/ijhpm.2014.78. 